Int. J. Electrochem. Sci., 15 (2020) $3180-3188$

\title{
Formation of Co-Ni Alloy Superlattices Composed of Face- centered Cubic (FCC) and Hexagonal Close Packed (HCP) Atomic Layers Using a Rectangular Pulse Voltage
}

\author{
M. Saitou \\ University of the Ryukyus, Department of Mechanical Systems Engineering, 1 Senbaru Nishihara-cho \\ Okinawa, 903-0213, Japan. \\ *E-mail: $\underline{\text { saitou@tec.u-ryukyu.ac.jp }}$
}

doi: $10.20964 / 2020.04 .42$

Received: 3 December 2019 / Accepted: 16 January 2020 / Published: 10 March 2020

Co-Ni alloy superlattices composed of face-centered cubic (FCC) and hexagonal close packed (HCP) atomic layers were electrodeposited using rectangular pulse voltages of 0.85 and $1.1 \mathrm{MHz}$, respectively. The energy dispersive X-ray spectroscopy and X-ray diffraction (XRD) data demonstrated that the Co$\mathrm{Ni}$ alloy superlattices electrodeposited at 0.85 and $1.1 \mathrm{MHz}$ formed face-centered cubic (FCC) and hexagonal close packed (HCP) atomic layers containing 35.5 and $14.4 \mathrm{wt} \% \mathrm{Ni}$, respectively. In addition, the XRD analyses demonstrated that the $\mathrm{Co}-\mathrm{Ni}$ alloy superlattices designed to exhibit the lattice constants of 0.5 and $1.0 \mathrm{~nm}$ showed one and two Bragg diffraction peaks, respectively, in the smallangle X-ray scattering region. The lattice constants calculated from the Bragg diffraction angles were approximately consistent with the designed lattice constants of 0.5 and $1.0 \mathrm{~nm}$.

Keywords: Co-Ni alloy; Superlattice; FCC; HCP: Lattice constant

\section{$\underline{\text { FULL TEXT }}$}

(C) 2020 The Authors. Published by ESG (www.electrochemsci.org). This article is an open access article distributed under the terms and conditions of the Creative Commons Attribution license (http://creativecommons.org/licenses/by/4.0/). 